\title{
Does Learning English Require Grit? Examining the Differential Effects on Grades in Core Subjects
}

\author{
Cecilia Thorsen, Department of Social and Behavioral Studies, University West \\ (iD https://orcid.org/0000-0002-7751-3942 \\ cecilia.thorsen@hv.se
}

\section{Stefan Johansson, Department of Education and Special Education, University of Gothenburg \\ https://orcid.org/0000-0002-2051-7248}

stefan.johansson@gu.se

Kajsa Yang Hansen, Department of Education and Special Education, University of Gothenburg

iD https://orcid.org/0000-0001-7071-2482

kajsa.yang-hansen@ped.gu.se

\begin{abstract}
Research indicates that beliefs on the locus of the primary source of learning can have negative effects on learning behaviors in school (Mercer \& Ryan, 2011). To an increasing extent, young people in Sweden acquire English outside school through different cultural practices (Sundqvist \& Sylvén, 2012). At the same time, students lack enthusiasm in English lessons, which can lead to a reduced investment of effort in the language classroom (Henry, 2014). However, learning a language requires both interest and effort. In psychological research, the capacity of showing consistency in interest and perseverance to achieve a goal, such as learning a language, is defined as grit (Duckworth et al., 2007). Studies investigating the association between grit and language achievement remain scarce. The present study contributes to filling this gap by investigating whether the effects of grit differ across different performance domains (i.e., English, Swedish and Mathematics). An additional purpose is to investigate whether there are differential effects of grit for subgroups of students with different SES, achievement levels, and gender. A total of 4646 compulsory school students born in 1992 were extracted from the Evaluation Through Follow-up Database (ETF). Multiple-group path analysis was used to examine the mechanisms of the grit facets (i.e., interest and perseverance) across time and subgroups. While both interest and perseverance predicted grades in Swedish and Mathematics, interest alone predicted grades in English. The low SES high achieving group also showed higher consistency in interest and perseverance than the other groups, indicating that grit could be more valuable in face of adversities.
\end{abstract}

Keywords: grit, perseverance, interest, L2 English, evaluation through follow-up (ETF)

This work is licensed under the Creative Commons Attribution-ShareAlike 4.0 International agreement (CC BY-SA 4.0). http://creativecommons.org/licenses/by-sa/4.0/
Journal for the Psychology of Language Learning ISSN: $2642-7001$

(2021) Volume 3, Issue 2, pp. 61-85 https://doi.org/10.52598/jp11/3/2/5 


\section{INTRODUCTION}

Research shows that students' experiences of learning English are markedly different depending on whether learning takes place in or outside school. Henry (2014), for example, concludes that compared to encounters with English in school, young people can experience leisure time encounters as more meaningful and engaging. This can cause a dissonance between in-school and out-of-school English, where young people believe that they learn as much or more English outside school as in school (Ushioda, 2013). Such beliefs about the primary source of learning can negatively affect students' in-school learning behaviors (e.g., Henry, 2014; Henry \& Cliffordson, 2017; Mercer \& Ryan, 2011). Consequently, students can invest less effort, and are less likely to persevere in the language classroom (Philip \& Duchesne, 2016). Hence, there are reasons to believe that the nature and amount of time spent on English activities outside the school will affect how students invest in language learning in school.

In Sweden, English is acquired outside school to an increasing extent. Such out-of-school acquisition constitutes an integral part of young people's cultural practices, and has become a parallel process that positively affects students' language acquisition and proficiency (Sundqvist, 2009; Sundqvist \& Sylvén, 2012; Sundqvist \& Wikström, 2015). At the same time, the Swedish School Inspectorate (2011) found that students lack enthusiasm in English lessons and believe that the tasks they get are too easy, so much so that students can experience two different cultures of English, one in and one outside school. Hence, the current state of English learning may differentially affect the investments students make in different school subjects, and their willingness to struggle through educational adversities encountered in school.

Language learning is a long-term process that demands strategies for sustaining interest and effort (Dörnyei, 2020). In psychological research, the capacity of holding consistent interest and perseverance of effort is defined as grit (Duckworth et al., 2007). Few studies, however, have investigated how grit is associated with second language acquisition and achievement, particularly when English has a ubiquitous status in society, and in contexts where students believe their English learning occurs mostly outside school.

\section{LITERATURE REVIEW}

\section{Grit}

Grit is a domain-general psychological trait characterized by having perseverance of effort and consistency of interest, and is positively associated with various life outcomes (Eskreis-Winkler et al., 2014). Grit entails the capacity for "working strenuously toward challenges, maintaining effort and interest over years despite failure, adversity, and plateaus in progress," and is held to increase with age (Duckworth, et al., 2007, p. 1087; Duckworth \& Quinn, 2009). Gritty individuals are typically depicted as being able to stay on task despite feelings of boredom, an ability regraded as essential for achievement (Duckworth et al., 2007). Additionally, grit has been advocated as a key predictor of school success, having an effect over and above intelligence (e.g., Duckworth et al., 2007), particularly in contexts with high adversity levels (Duckworth \& Gross, 2014).

The literature shows that grit is associated with range of positive factors including academic effort (e.g., time spent on practice) learning outcomes (Duckworth et al., 2011), high-school graduation (Light \& Nencka, 2019), retention (Eskreis-Winkler et al., 2014), academic performance (Li et al., 2018) and student well-being (Datu et al., 2016; Disabato et al., 2019; Vaino \& Daukantaitè, 2016). Findings suggest that grittier individuals are better able to use their capabilities, find it easier to engage in extended learning practices, and are less likely to be distracted (Duckworth et al., 2011). However, studies have also shown a limited value of grit in predicting academic achievement (e.g., Credé, 2018; Credé et al., 2017).

\section{Measuring Grit for Predicting Academic Achievement}

While Duckworth et al. (2007) identified grit as a combination of the two constructs consistency of interest and perseverance of effort, several studies have indicated that the two facets might have a differential effect in predicting performance in different domains. In a metaanalytic study by Credé, et al. (2017), the overall grit score appears to be a modest predictor of academic achievement $(r=.18)$. However, the perseverance facet of grit was found 
to have a higher relationship with achievement $(r=.26)$ than the consistency of interest factor $(r=.10)$, or overall grit ( $r$ $=.18)$. These results are echoed in studies where the two facets of grit are considered separately. Specifically, consistency of interests typically contributes with little (if any) predictive power, while perseverance of effort is a much stronger predictor of achievement, independently of interest (e.g., Bowman et al., 2015; Chang, 2014; Jiang et al., 2019; Morell et al., 2020; Muenks et al., 2017; Rimfeld et al., 2016; Wolters \& Husain, 2015). Credé (2018) even argues that it is not possible to combine the consistency of interest and perseverance of effort factors into a single variable, since being high in perseverance, but low in interest will be equated with the vice versa scenario. Identifying grit as a higher-order construct (e.g., Duckworth \& Quinn, 2009) has also proven problematic since the model is unidentified at the higher level (e.g., Credé, 2018; Muenks et al., 2017). Since grit as a whole only modestly predicts achievement, Credé et al. (2017) have suggested that future research should focus on the two facets separately and, in particular, should focus on the perseverance facet of grit.

The modest predictive power of grit on academic achievement could also be explained by the relation being moderated by other factors. Credé et al., (2017) have suggested that the performance domain itself might moderate the relationship between grit and academic performance (e.g., Macnamara et al. 2014). Typically, grit is effective in challenging tasks that require high levels of effort and practice. Hence, it can be hypothesized that different school performance domains may differ in the degree to which grit is necessary to succeed. In the Swedish context, many students find school English relatively easy and not particularly challenging (the Swedish School Inspectorate, 2011). It is therefore of interest to examine how grit functions in the context where, as a school subject, learning English is not seen as particularly hard.

\section{Domain-General or Domain-Specific?}

The modest predictive power of grit has been explained in the sense that it may not represent the domain-general trait as originally suggested by Duckworth et al. (2007) (e.g., Cormier et al., 2019; Shmidt et al., 2017). Rather, results have indicated that measures of domain-specific grit are more closely related to achievement (e.g., Cormier et al., 2019; Schmidt et al., 2017), and that the level of grit can differ between different situational contexts (e.g., Cormier et al., 2019). Additionally, school-specific grit has been shown to explain more variance in high-school GPA than the overall grit measure (e.g., Schmidt et al., 2019). In a sample of 757 adolescents, Clark and Malecki (2019) investigated the properties of an academic grit scale in measuring domain-specific grit. The results showed that the scale had high internal consistency and construct validity. Moreover, they also found positive associations between the academic grit scale, GPA scores, and self-reported achievement. The domain-specific grit scale also provided incremental validity over and above general grit. Similar results have been reported within SLA research (e.g., Sudina et al. 2020; Teimouri et al. 2020).

\section{Group Differences in Grit}

Research on gender differences in grit is inconclusive. For example, Usher et al., (2019) found that girls reported being grittier than boys (see also, e.g., Christensen \& Knezek, 2014). Other studies, however, have not found any significant gender differences in grit (e.g., Bazelais et al., 2016; Hodge et al., 2017).

Studies have also shown differences in grit across students with different levels of socioeconomic status (SES). Students with lower SES report significantly lower grit than students with higher SES (e.g., Usher, 2019). However, research has also shown differential effects of grit for low SES students, depending on their achievement level. For example, Huang and Zhu (2017) found that for the low SES students who in PISA testing achieved above average in Mathematics and science, grit was significantly associated with achievement. Additionally, Thorsen et al. (2021) found that resilient students are more consistent in both interest and perseverance over time.

Research on grit has also revealed differentiated effects for low- and high-ability students. In demanding situations, low-ability students substitute their ability with a higher level of grit, while high-ability students' ability is complemented by grit (Light \& Nencka, 2019). These findings indicate that grit might be more valuable in circumstances of adversity, and across different subgroups. 
Hence, the value of grit should be investigated in different subpopulations of students.

\section{Grit in SLA}

So far, studies of grit in SLA contexts are generally rare. In one study, Changlek and Palanukulwong (2015) examined the relationships between motivation, anxiety, and grit among high and low achievers. The results showed that high achievers tended to have higher levels of grit which is positively related to motivation in L2 learning. On the other hand, Feng and Papi (2020), who investigated the relation between grit, future L2 selves, L2 motivational intensity and L2 persistence among 94 university students studying Chinese as a foreign language, obtained differing results; in line with several of the aforementioned studies (e.g., Credé et al., 2017), only perseverance of effort predicted motivational intensity and L2 persistence. Interestingly, the ideal L2 self - the speaker of the language one ideally wants to be-mediated the relation between perseverance and L2 persistence, suggesting that the act of working hard is only displayed when the goal of L2 learning has personal value.

In studies investigating the association between grit and measures of L2 achievement, results are inconsistent. For example, Wei et al. (2019) examined the effect of grit on foreign language performance and the mediating role of foreign language enjoyment and classroom environment in a sample of Chinese middle school students. They found that, when controlling for students' gender and age, grit directly affected both foreign language learning performance and enjoyment. However, these results were not mirrored by Khajavy et al. (2020) when investigating the relationships between language mindsets and grit, and their respective roles in predicting L2 achievement in a sample of 1,178 university students in Iran. In concordance with previous research, they confirmed that grit should not be considered a unitary construct, and that the grit-facets should be considered separately. The results showed that while a growth mindset weakly predicted L2 achievement (.15), neither the perseverance nor interest facet of grit contributed with any predictive power. Reviewing these findings, Khajavy et al. (2020) argued that the results might be moderated by the performance domain, i.e., that displaying grit would be more valuable when the task is well-defined and challenging. In accordance with previous studies, Khajavy et al. (2020) also argue that the lack of predictive power could be explained by the domain-general definition of grit.

Hence, the inconsistencies in these previous studies might be explained by the use of domain-general measures of grit, and the overlooking of context-specific variations. To address these issues, Teimouri et al. (2020) constructed a language-specific grit-scale related to motivational and emotional characteristics, and measures of L2 achievement in an Iranian context. Their results indicated that L2 grit was positively associated with motivational variables (i.e., intended effort, L2 willingness to communicate, attention and teacher perception), and that it positively predicted language achievement. At the same time, domain-general grit showed only weak or no relationship with the motivational and achievement measures.

Some studies have found a significant and positive relationship between L2 grit and self-perceived English proficiency among university students (e.g., Sudina et al., 2020; Wei et al., 2020). The nature of these relationships differed between students studying English as a foreign language (EFL), and those studying English as a second language (ESL). Moreover, while the two groups of students differed significantly in their perseverance of effort, this was not the case in relation to consistency of interest (Sudina et al., 2020). Interestingly, perseverance of effort positively predicted self-perceived proficiency only among EFL-students, while the consistency of interest was a significant negative predictor of self-perceived proficiency among ESL-students (Sudina et al., 2020).

In sum, studies within SLA reveal a differentiated function of grit across different student sub-populations and domains, thus calling for further exploration (Sudina et al., 2020; Teimouri et al. 2020; Wei et al. 2020). Results from both mainstream educational psychology (e.g., Schmidt et al., 2019) and SLA (e.g., Teimouri et al, 2020) also indicate that the domain-general measure of grit is not sufficient in predicting behavior within specific domains, this since it overlooks among other things how interest in a particular subject can lead to effortful behavior. Moreover, the majority of studies seem to focus on university students. It is important therefore that research is extended to other educational contexts, such as compulsory education, and to examine how grit influences second language learning at school. Finally, since grit entails the capacity for "working 
strenuously toward challenges, maintaining effort and interest over years, despite failure, adversity, and plateaus in progress" (Duckworth, et al., 2007, p. 1087), a longitudinal perspective is warranted. It is important that changes in grit and its effects on SL learning are studied over time (Dörnyei, 2020).

\section{Purpose and Aims}

The present study aims to investigate the association between grit and second language achievement in Sweden. Since second language learning is a long-term process that requires the individual to invest both effort and interest (Dörnyei, 2020), the focus is directed to the differentiated effect of interest and perseverance on achievement in English (as measured by school grades). A further aim is to explore the effects of the performance domain (e.g., Credé et al., 2017) by examining whether influences differ between English and other subjects (Swedish and Mathematics)). School-specific grit will be used in the present study, this since previous studies have indicated stronger relations with achievement (e.g., Clark \& Malecki, 2019; Teimouri et al., 2020).

\section{Research Questions}

1. What are the effects of the grit facets of interest and perseverance on achievement in English in grade 6 and grade 9, compared to those in Swedish and Mathematics? Do these effects differ across SES and achievement subgroups?

2. How do interest and perseverance affect English achievement over time? Does the mechanism differ in Swedish and Mathematics, and across gender, SES and achievement subgroups?

\section{METHOD}

Data was retrieved from the Evaluation through Follow-up (ETF) database, a longitudinal accumulation of data that draws on a $10 \%$ nationally representative sample for each of ten birth cohorts in Sweden. The samples are selected based on a stratified selection of 35 municipalities, followed by a random selection of 227 school areas. Within these areas, all students were included. The Swedish school system has nine years of compulsory school, and students start school at age 7. They were followed up in grades 6 and 9 of compulsory school, and again in upper secondary school (Härnqvist, 2000). In the present study, 4,646 individuals born in 1992 were included. The complete 1992 sample consists of 10,147 individuals. However, only those who completed questionnaires in both grades 6 and $9(N=$ $4,646)$ have been selected. In this sample, $46.8 \%$ were males and $53.2 \%$ females.

These individuals were also divided into subgroups on the basis of their SES and achievement level on National Tests in English, Swedish and Mathematics. Parents' highest education at or below upper secondary level was used as the cutoff for the low vs high SES group. The average achievement of the overall score in all national test subjects for students in Sweden divides students into the high vs the low achievement group. The two cutoff values assigned students into four subgroups. One group consisted of the low SES individuals whose national test score was above the country mean (LSHA, $n=493$ ). The other group consisted of low SES individuals whose national test score was below the average (LSLA, $n=1164$ ). Two additional groups included high SES students. One group where students achieved below average on the national test (HSLA, $n=1191$ ), and another where they achieved above the average (HSHA, $n=1800$ ). With the total selected sample as a reference, these four subgroups were compared.

\section{Measures}

\section{SES and Gender}

The 6-scaled parents' highest education level (SUN6) is used to measure SES. The categories included no information, compulsory school, vocational upper secondary education, academic upper secondary education, three-year or less university education, four-year or more university education. Using parents' highest education level as an indicator for SES is justified since it corresponds well with social class divisions in Sweden (Svensson et al., 2007). Gender is coded as a dummy variable (boys $=0$, girls $=1$ ). 


\section{National Test}

The national test scores in grade 9 measure students' school achievement and are used to create subgroups. The tests include the three core subjects: English, Swedish and Mathematics. Each test is constructed to cover large parts of each curriculum, the purpose being to aid teachers in their grading. For each test, a fail grade corresponds to zero credit points, a pass corresponds to ten credit points, a pass with distinction corresponds to fifteen credit points, and a pass with special distinction corresponds to twenty credit points. A continuous variable for the different subject test scores was created using principal component analysis.

\section{Grades}

The grades used in the present study are from the leaving certificate in grade 9 of compulsory school. In Sweden, grades have high-stakes status and are used for selection to upper secondary education. The grading scale for the 1992 sample encompasses four different steps, the same as in the abovementioned national test. School grades in English, Swedish and Mathematics are used as the distal outcome.

\section{Grit}

In the ETF database, indicators used to measure perseverance are adapted for children in the school setting. Also, the measure of interest is contextualized to measure students' interest in learning different school subjects. Even though Duckworth et al., (2007; 2009) formulated a domain-general goal-oriented interest dimension, research on interest within educational psychology (e.g., Hidi \& Renninger, 2006) justifies a content-specific measure of interest. Data on both perseverance and interest was collected in grades 6 and 9 of compulsory school.

\section{Interest}

Information on student's interest in learning different subjects was captured by their responses to the question How interested are you in learning: English, Swedish, Mathematics. In grade 6, answers are given on a 5-point
Likert scale, ranging from very interested, to very uninterested. In grade 9, answers are given on a 4-point Likert scale also ranging from very interested, to very uninterested. Since the scales were not equal between grades, standardized scores were used.

\section{Perseverance}

Perseverance is measured by students' responses to the question How often do you try to do the following things in school on a 5-point Likert scale in both grade 6 and grade 9: (1) I give up if I get a difficult task; (2) I always do my best; (3) I work hard even if it is difficult; (4) I get things done in time. The alpha coefficient for grade 6 was .68 and .75 for grade 9. The alpha level in grade 6 is somewhat lower. However, alphas around .70 are considered acceptable (Kline, 2015). A continuous Perseverance variable was created from the four items using the factor scores generated by a principal component analysis (PCA) (for detailed information from PCA see Appendix).

Table 1 presents the descriptive statistics for the total sample, and in the four subgroups. All variable means in the LSHA and the HSHA groups are generally higher than those in the LSLA and HSLA groups. Descriptive statistics for the full sample can be found in Appendix.

\section{Data Analysis}

The current study took advantage of path analysis. Based on regression techniques, this allows the modelling of relations among variables, both direct and indirect. A variable in a path model can be both dependent and independent. The analysis was carried out stepwise. First, path models for the total sample and the four subgroups were estimated, where interest and perseverance in grade 6 affected the subject grades in English, Swedish, and Mathematics (see Figure 1). Secondly, an identical model structure was fitted to the grade 9 data for all groups. Finally, three path models for each subject (English, Swedish and Mathematics) were set up and tested for the total sample, and for the four subgroups (i.e., LSHA, LSLA, HSLA and HSHA groups), where interest and perseverance in grade 9 were regressed on their grade 6 counterpart, and together affected the subject grades (see Figure 2). Gender was related to interest, perseverance, 
and subject grades. The final model permitted investigation of the mechanisms of interest and perseverance on students' academic outcomes across time and subgroups. The full information maximum likelihood (FIML) estimation was used to estimate the missing values. All analyses were conducted using Mplus 8.4 (Muthén \& Muthén, 1998-2017). All estimated models are saturated (i.e., just identified model) with perfect model fit.

Table 1. Descriptive Statistics for SES-Achievement Groups, Divided by Grade 6 and Grade 9

\begin{tabular}{|c|c|c|c|c|c|c|}
\hline & $N$ & $M$ & $S D$ & $N$ & $M$ & $S D$ \\
\hline \multirow{2}{*}{ Variables } & & Grade 6 & & & Grade 9 & \\
\hline & \multicolumn{6}{|c|}{ Low SES - high achievement (LSHA) } \\
\hline Grade English & & & & 492 & 17.06 & 2.72 \\
\hline Grade Swedish & & & & 480 & 16.58 & 2.87 \\
\hline Grade Mathematics & & & & 492 & 14.82 & 3.53 \\
\hline Perseverance total & 488 & 0.12 & 0.94 & 482 & 0.230 & 0.92 \\
\hline Get things done in time & 491 & 0.16 & 0.89 & 486 & 0.115 & 0.94 \\
\hline Work hard even when difficult & 491 & 0.01 & 1.00 & 487 & 0.167 & 0.95 \\
\hline Always do my best & 489 & 0.09 & 0.94 & 489 & 0.194 & 0.89 \\
\hline Easily give up & 491 & 0.11 & 0.91 & 490 & 0.247 & 0.92 \\
\hline Interest in English & 491 & 0.06 & 1.00 & 489 & 0.311 & 0.81 \\
\hline Interest in Swedish & 490 & 0.07 & 0.96 & 488 & 0.195 & 0.98 \\
\hline \multirow[t]{2}{*}{ Interest in Mathematics } & 489 & 0.03 & 0.96 & 491 & 0.111 & 1.01 \\
\hline & \multicolumn{6}{|c|}{ Low SES - low achievement (LSLA) } \\
\hline Grade English & & & & 1161 & 11.20 & 3.38 \\
\hline Grade Swedish & & & & 1113 & 11.33 & 2.95 \\
\hline Grade Mathematics & & & & 1161 & 10.05 & 3.61 \\
\hline Perseverance total & 1129 & -0.18 & 1.06 & 1134 & -0.24 & 1.04 \\
\hline Get things done in time & 1148 & -0.15 & 1.04 & 1151 & -0.13 & 1.02 \\
\hline Work hard even when difficult & 1142 & -0.07 & 1.05 & 1147 & -0.17 & 1.01 \\
\hline Always do my best & 1135 & -0.06 & 1.08 & 1148 & -0.12 & 1.07 \\
\hline Easily give up & 1155 & -0.24 & 1.06 & 1152 & -0.34 & 1.01 \\
\hline Interest in English & 1150 & -0.10 & 1.06 & 1143 & -0.33 & 1.09 \\
\hline Interest in Swedish & 1151 & 0.02 & 1.01 & 1146 & -0.19 & 1.00 \\
\hline \multirow[t]{2}{*}{ Interest in Mathematics } & 1150 & 0.00 & 1.02 & 1142 & -0.25 & 1.00 \\
\hline & \multicolumn{6}{|c|}{ High SES - low achievement (HSLA) } \\
\hline Grade English & & & & 1188 & 12.23 & 3.10 \\
\hline Grade Swedish & & & & 1159 & 12.29 & 2.94 \\
\hline Grade Mathematics & & & & 1188 & 11.31 & 3.11 \\
\hline Perseverance total & 1144 & -0.06 & 0.99 & 1163 & -0.12 & 0.96 \\
\hline Get things done in time & 1169 & -0.08 & 1.02 & 1177 & -0.05 & 0.97 \\
\hline Work hard even when difficult & 1160 & 0.00 & 1.01 & 1181 & -0.11 & 0.96 \\
\hline Always do my best & 1154 & -0.02 & 1.03 & 1177 & -0.09 & 1.00 \\
\hline Easily give up & 1174 & -0.11 & 1.02 & 1183 & -0.12 & 0.96 \\
\hline Interest in English & 1179 & -0.06 & 1.02 & 1171 & -0.19 & 1.04 \\
\hline Interest in Swedish & 1181 & -0.03 & 1.03 & 1176 & -0.18 & 0.99 \\
\hline \multirow[t]{2}{*}{ Interest in Mathematics } & 1176 & 0.00 & 1.00 & 1169 & -0.12 & 0.97 \\
\hline & \multicolumn{6}{|c|}{ High SES - high achievement (HSHA) } \\
\hline Grade English & & & & 1796 & 17.31 & 2.71 \\
\hline Grade Swedish & & & & 1788 & 17.02 & 2.90 \\
\hline Grade Mathematics & & & & 1796 & 15.97 & 3.53 \\
\hline
\end{tabular}




\begin{tabular}{lllllll} 
Perseverance total & 1770 & 0.16 & 0.92 & 1753 & 0.22 & 0.93 \\
Get things done in time & 1793 & 0.15 & 0.92 & 1775 & 0.13 & 0.98 \\
Work hard even when difficult & 1787 & 0.06 & 0.94 & 1773 & 0.17 & 0.96 \\
Always do my best & 1783 & 0.05 & 0.91 & 1773 & 0.11 & 0.94 \\
Easily give up & 1793 & 0.25 & 0.88 & 1785 & 0.30 & 0.89 \\
Interest in English & 1793 & 0.11 & 0.91 & 1789 & 0.26 & 0.84 \\
Interest in Swedish & 1793 & -0.01 & 0.97 & 1792 & 0.19 & 0.94 \\
Interest in Mathematics & 1790 & 0.01 & 0.96 & 1783 & 0.22 & 0.96 \\
\hline
\end{tabular}

Figure 1. Multi Group Path Model of Perseverance and Interest for Grade 6 and 9.

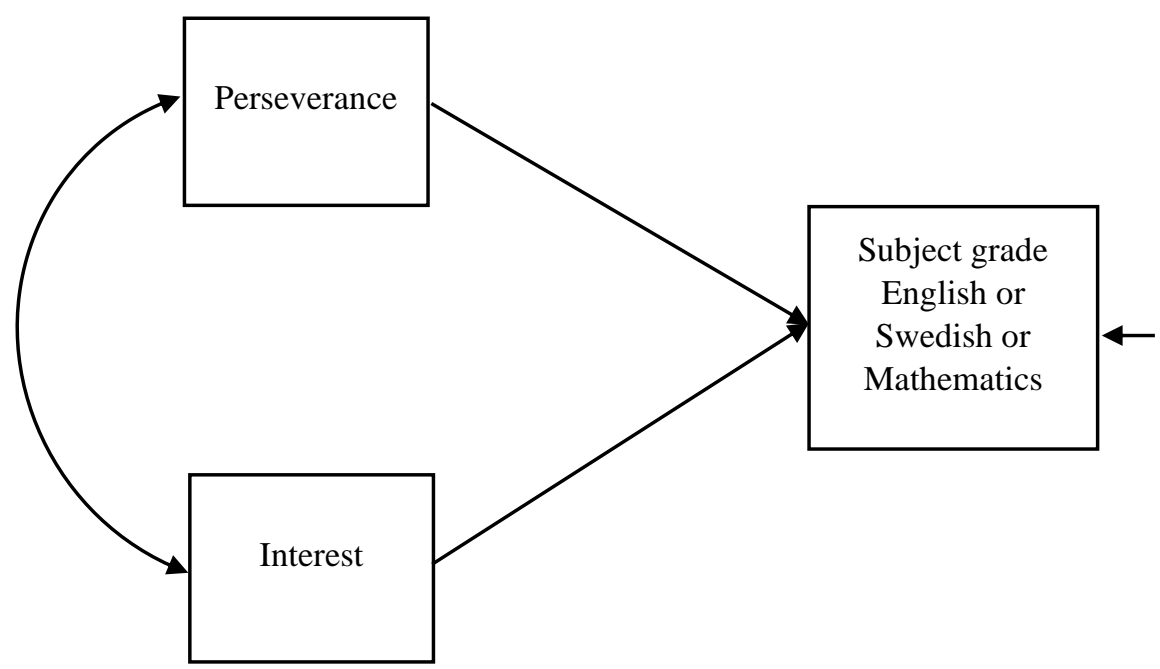

\section{RESULTS}

\section{Effects of Grit on Achievement in English, Swedish and Mathematics for Grade 6 and Grade 9}

To answer the first research question, the effects of grit on achievement in English, Swedish and Mathematics were examined separately for subgroups in both the $6^{\text {th }}$ and $9^{\text {th }}$ grade. The effects were estimated and compared in multiple group path models (Model A1 - Model C2). In each model, perseverance and interest in the specific school subject was related to the subject grade (see Figure 1). In Table 2, the effects of perseverance and interest on each school subject and grade are presented.

\section{English}

In grade 6 , perseverance was not significantly related to the grade in English for any of the student groups, except for the LSLA-group (.07). However, interest in English was positively related to the English grade for all groups, ranging from (.08) for the HSHA group to (.17) for the LSHA group. In grade 9, no significant effect was found of perseverance on the English grade in any of the subgroups. A relatively even effect of interest was observed, around .15, on the English grade for all groups. The $R^{2}$ for both models was generally low, indicating that the variation explained by the model was low.

\section{Swedish}

In grade 6, significant effects of interest and perseverance on the Swedish subject grade were observed only in a few groups. Perseverance affected students' Swedish grade in both the LSHA and LSLA groups (.16 and .11 respectively), and a positive effect of interest in Swedish for the HSHA group (.11). In grade 9, both perseverance and interest in 
Swedish were significantly related to the Swedish subject grade in all groups. The effect of perseverance was clearly the largest for the LSHA group (.24). The highest effect of interest on Swedish grade was for the HSHA group (.29). However, the $R^{2}$ was generally low, except for the two high achieving groups (LSHA and HSHA) in grade 9 (see Model B2 results in Table 2).

Table 1. Standardized Effects for Multiple Group Path Models A1-C2 with Subject Grades in English, Swedish or Mathematics as Dependent Variables

\begin{tabular}{|c|c|c|c|c|}
\hline & $\mathrm{LSHA}^{1}$ & LSLA $^{2}$ & $\mathrm{HSLA}^{3}$ & $\mathrm{HSHA}^{4}$ \\
\hline & \multicolumn{4}{|c|}{ Model A1 English Grade 6} \\
\hline PersGr6 $\rightarrow$ Grade English & ns & .07 & ns & ns \\
\hline InterEngGr6 $\rightarrow$ Grade English & .17 & .09 & .11 & .08 \\
\hline PersGr6 withInterEngGr6 & .30 & .24 & .25 & .25 \\
\hline \multirow[t]{2}{*}{$R^{2}$} & .03 & .02 & .02 & .01 \\
\hline & \multicolumn{4}{|c|}{ Model A2 English Grade 9} \\
\hline PersGr9 $\rightarrow$ Grade English & ns & ns & ns & ns \\
\hline InterEngGr9 $\rightarrow$ Grade English & .16 & .14 & .15 & .18 \\
\hline PersGr9 with InterEngGr9 & .30 & .37 & .32 & .24 \\
\hline \multirow[t]{2}{*}{$R^{2}$} & .03 & .03 & .03 & .04 \\
\hline & \multicolumn{4}{|c|}{ Model B1 Swedish Grade 6} \\
\hline PersGr6 $\rightarrow$ Grade Swedish & .16 & .11 & ns & ns \\
\hline InterSweGr6 $\rightarrow$ Grade Swedish & ns & ns & ns & .11 \\
\hline PersGr6 with InterSweGr6 & .34 & .31 & .28 & .31 \\
\hline \multirow[t]{2}{*}{$R^{2}$} & .03 & .01 & .01 & .01 \\
\hline & \multicolumn{4}{|c|}{ Model B2 Swedish Grade 9} \\
\hline PersGr9 $\rightarrow$ Grade Swedish & .24 & .15 & .17 & .13 \\
\hline InterSweGr9 $\rightarrow$ Grade Swedish & .21 & .14 & .19 & .29 \\
\hline PersGr9 withInterSweGr9 & .33 & .37 & .35 & .29 \\
\hline \multirow[t]{2}{*}{$R^{2}$} & .14 & .06 & .08 & .12 \\
\hline & \multicolumn{4}{|c|}{ Model C1 Mathematics Grade 6} \\
\hline PersGr6 $\rightarrow$ Grade Mathematics & ns & ns & ns & .06 \\
\hline InterMatGr6 $\rightarrow$ Grade Mathematics & .22 & $.07 n s$ & .13 & .15 \\
\hline PersGr6 with InterMatGr6 & .45 & .38 & .35 & .36 \\
\hline \multirow[t]{2}{*}{$R^{2}$} & .05 & .01 & .02 & .03 \\
\hline & \multicolumn{4}{|c|}{ Model C2 Mathematics Grade 9} \\
\hline PersGr9 $\rightarrow$ Grade Mathematics & .13 & .11 & .09 & .09 \\
\hline InterMatGrg $\rightarrow$ Grade Mathematics & .39 & .10 & .18 & .42 \\
\hline PersGr9 with InterMatGr9 & .33 & .39 & .32 & .37 \\
\hline$R^{2}$ & .20 & .03 & .05 & .21 \\
\hline
\end{tabular}

Note. PersGr6 - Perseverance grade 6, PersGr9 - Perseverance grade 9, InterEngGr6 - Interest in English grade 6, InterEngGr9 - Interest in English grade9, InterSweGr6 - Interest in Swedish grade 6, InterSweGr9 - Interest in Swedish grade 9, InterMatGr6 - Interest in Mathematics grade 6, InterMatGr9 - Interest in Mathematics grade 9, ns - non-significant estimate. ${ }^{1}$ Low SES and high achievement group. ${ }^{2}$ Low SES - low achievement group. ${ }^{3}$ High SES - low achievement group. ${ }^{4}$ High SES - high achievement group. 


\section{Mathematics}

Perseverance in grade 6 was only significantly related to the subject grade in Mathematics in the HSHA group. Significant effects of interest in grade 6 were found in the LSHA group (.22), the HSLA group (.13), and the HSHA group (.15). In grade 9, perseverance was significantly related to the Mathematics grade in all groups, although the effects were relatively modest. Interest in Mathematics was substantially related to the subject grade in Mathematics for the LSHA group (.39), and for the HSHA group (.42). The $\mathrm{R}^{2}$ for Model $\mathrm{C} 1$ and Model C2 were generally low, as in the previous models. However, $\mathrm{R}^{2}$ was somewhat higher for Model C2 (Model C2, Table 2).
While perseverance in grade 6 has no major effect for any of the subjects, it is of substantial importance only for Swedish and Mathematics in grade 9. A possible explanation is that since demands increase as students progress through school grades, so does the need to persevere and be gritty. Interest explains achievement only in English. The LSHA students seem to be higher on both interest and perseverance level in Swedish and Mathematics, and have considerably higher relations with the subject grades in the two subjects.

Figure 2. The Longitudinal Model of Perseverance and Interest

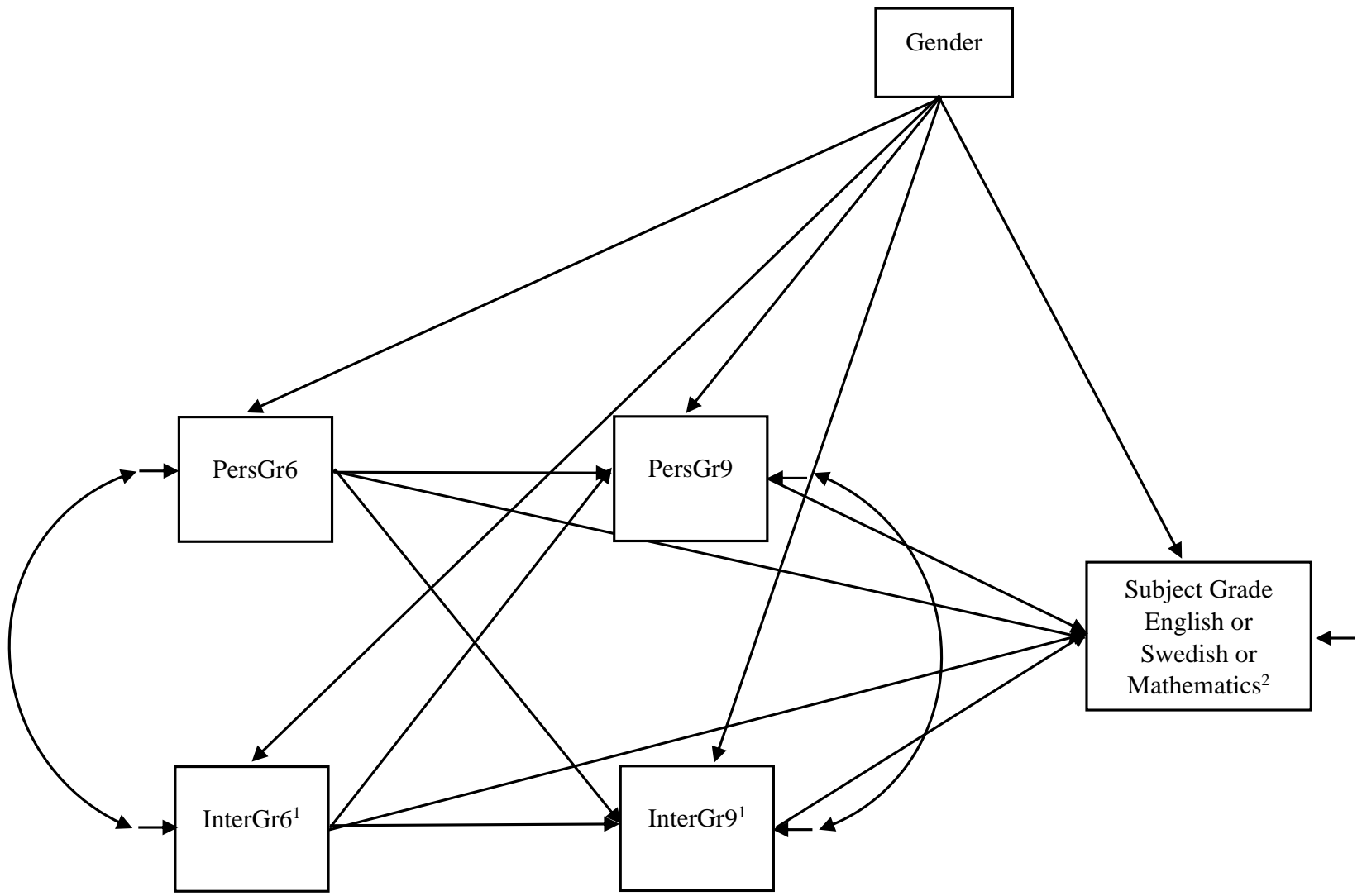

Note. PersGr6 - Perseverance in grade 6, PersGr9 - Perseverance in grade 9, InterGr6 - Interest in grade 6, InterGr9 Interest in grade 9. ${ }^{1}$ Interest is measured as the subject-specific interest in grade 6 and 9 respectively in each model (Model D1-D3). ${ }^{2}$ The distal outcome is the subject grade in each subject: Model D1 English, Model D2 Swedish, Model D3 Mathematics. 


\section{Mechanisms of Perseverance and Interest-Longitudinal Modelling of Grit}

To examine the development of grit and its effect on school outcomes, a multiple group longitudinal path model of perseverance and interest in each subject was estimated. The grade 9 measures of perseverance and interest in each subject were regressed on their grade 6 counterparts, which in turn affected each respective subject outcome. In such a way, it became possible to investigate whether early grade interest and perseverance affect later interest and perseverance; that is if students are consistent in their interests and perseverance over time. Moreover, by identifying cross-lagged effects, it is also possible to investigate how previous levels of interest affect later perseverance, and vice versa. Gender differences were also investigated in the models by regressing perseverance and interest and the subject outcomes on gender (see Figure 2). The saturated models are just-identified models and have perfect model fit.

\section{Model D1 Longitudinal model of English}

When investigating the mechanisms of grit for English longitudinally, a similar pattern was observed as in the onetime model. Perseverance did not predict the subject grade in English in either the two school grades or subgroups. Interest in English in grade 9 was, however, significantly related to the English grade in all groups, ranging from (.14) for the LSLA group, and (.20) for the HSHA group. For the LSHA and the HSLA groups, there were also significant direct effects of interest on the subject grade in English, these being .15 and .07 , respectively. A significant crosslagged effect was found in the LSHA, LSLA and HSLA subgroups, implying that perseverance in grade 6 affected their later grade interest $(.10, .08, .08$, respectively). For the low achieving students (LSLA and HSLA groups), interest in grade 6 also affected perseverance in grade 9 (.13 and .12, respectively) (Model D1, Table 3).

Indirect effects of perseverance and interest in grade 6 on the subject grade in English were also identified. While indirect effects of interest in grade 6 on the subject grade in English were significant for all groups, perseverance in grade 6 indirectly affected the subject grade in English only for the low achieving students (Model D1, Table 4).
No gender differences could be observed in grade 6 perseverance for any of the groups. However, in grade 9, girls reported higher levels of perseverance for all groups, being (.15) in LSHA, (.08) in LSLA, (.17) in HSLA, and (.15) in HSHA. Controlling for both perseverance and interest in English, no significant direct effects of gender on the subject grade in English was noted for any group. There were, however, significant indirect effects of gender on the subject grade in English, mediated through interest in English. The LSHA group had the highest total indirect effect of gender on the subject grade in English (.06), and the LSLA group the lowest (.02). This indicates that girls, through their relatively higher interest level in English, gain somewhat higher grades (Model D1, Table 4).

\section{Model D2 and D3 Longitudinal model of Swedish and Mathematics}

The same model structure was applied to Swedish and Mathematics (Figure 2). Contrary to the results for English, significant direct effects of perseverance in grade 9 on the subject grade were found in both Swedish and Mathematics for all groups. Interest in Swedish at grade 9 also significantly influenced the Swedish grade in all groups, being highest in HSHA .24 and lowest in LSLA, with the remaining two groups being around (.17). The LSLA group also had direct effects of both perseverance (.06) and interest in grade 6 (.07) on the Swedish grade. Only in the grade 6 HSLA and HSHA groups were significant direct effects of interest in Mathematics on the subject grade found, these being (.08) and (.05), respectively. However, there were substantial effects of interest in Mathematics in grade 9 on the subject grade for the LSHA group (.37), LSLA group (.27), HSLA group (.23) and the HSHA group (.26). Cross-lagged effects were also found for both subjects and all groups except for the LSHA group. This implies that early grade interest affects later grade perseverance, and vice versa (Model D2 and D3, Table 3).

There were substantial gender effects on the subject grade in Swedish for all groups, being around (.23), indicating that girls had higher grades in Swedish. Only minor gender differences were found in Mathematics for the HSLA group (-.06), indicating a higher grade for boys in this group. Girls rated their interest in Swedish higher in both grade 6 and 9 in all groups. In Mathematics, however, 
only a small effect of gender on interest in grade 9 was observed for the LSLA group (.06). For the grade 6 perseverance, no gender difference could be found for either Swedish or Mathematics. There were significant gender effects for all groups on perseverance at grade 9 in Swedish and Mathematics, implying that girls regard themselves as more perseverant (Model D2 and D3, Table 3).

Moreover, gender affected Swedish grade indirectly in all groups; (.03) in the LSLA group, and around (.07) in the remaining groups. The indirect effects of grade 6 interest in Swedish on the subject grade were also significant for all groups, being about (.12) in the two high-achieving groups (LSHA and HSHA), and around (.04) in the two lowachieving groups (LSLA and HSLA). Significant indirect effects of grade 6 perseverance on the subject grade in Swedish were observed, being approximately (.05) for all groups (Model D2, Table 4).

In Mathematics, the significant indirect effect of gender only was found in the HSLA group (.02). However, the indirect effects of grade 6 interest in Mathematics on the subject grade were significant for all groups, again being higher for the two high-achieving groups (about .13), and lower for the low-achieving groups (about .05). Moreover, the grade 6 perseverance significantly and indirectly affected the Mathematics grade in all groups, although the effects were relatively small, about (.05). (Model D3, Table $4)$.

Table 3. Standardized Effects for Models D1-D3 (Longitudinal Models of Grit) with Subject Grade in English, Swedish and Mathematics as Outcome

\begin{tabular}{|c|c|c|c|c|}
\hline & LSHA $^{1}$ & LSLA $^{2}$ & HSLA $^{3}$ & $\mathrm{HSHA}^{4}$ \\
\hline & \multicolumn{4}{|c|}{ Model D1 Longitudinal Model - English } \\
\hline PersGr6 $\rightarrow$ PersGr9 & .37 & .30 & .35 & .33 \\
\hline PersGr6 $\rightarrow$ Grade English & ns & ns & ns & ns \\
\hline PersGr6 $\rightarrow$ InterEngGr9 & .10 & .08 & .08 & ns \\
\hline PersGr9 $\rightarrow$ Grade English & ns & ns & ns & ns \\
\hline InterEngGr6 $\rightarrow$ InterEngGr9 & .16 & .26 & .20 & .19 \\
\hline InterEngGr6 $\rightarrow$ Grade English & 15 & ns & .07 & ns \\
\hline InterEngGr6 $\rightarrow$ PersGr9 & ns & .13 & .12 & ns \\
\hline InterEngGr9 $\rightarrow$ Grade English & .17 & .14 & .15 & .20 \\
\hline PersGr6 with InterEngGr6 & .31 & .26 & .27 & .29 \\
\hline PersGr9 with InterEngGr9 & .25 & .30 & .24 & .21 \\
\hline Gender $\rightarrow$ PersGr6 & ns & ns & ns & ns \\
\hline Gender $\rightarrow$ PersGr9 & 15 & .08 & .17 & .15 \\
\hline Gender $\rightarrow$ Grade English & ns & ns & -.08 & -.02 \\
\hline Gender $\rightarrow$ InterEngGr6 & .06 & ns & ns & ns \\
\hline \multirow[t]{2}{*}{ Gender $\rightarrow$ InterEngGr9 } & .26 & .14 & .12 & .17 \\
\hline & \multicolumn{4}{|c|}{ Model D2 Longitudinal Model - Swedish } \\
\hline PersGr6 $\rightarrow$ PersGr9 & .34 & .31 & .34 & .30 \\
\hline PersGr6 $\rightarrow$ Grade Swedish & ns & .06 & ns & ns \\
\hline PersGr6 $\rightarrow$ InterSweGr9 & ns & .10 & .09 & ns \\
\hline PersGr9 $\rightarrow$ Grade Swedish & .22 & .16 & .16 & .13 \\
\hline InterSweGr6 $\rightarrow$ InterSweGr9 & .18 & .21 & .22 & .21 \\
\hline InterSweGr6 $\rightarrow$ Grade Swedish & ns & -.07 & ns & ns \\
\hline InterSweGr6 $\rightarrow$ PersGr9 & ns & .08 & .13 & .08 \\
\hline InterSweGr9 $\rightarrow$ Grade Swedish & .18 & .12 & .17 & .24 \\
\hline PersGr6 with InterSweGr6 & .36 & .32 & .29 & .32 \\
\hline PersGr9 with InterSweGr9 & .30 & .31 & .24 & .24 \\
\hline Gender $\rightarrow$ PersGr6 & ns & ns & ns & ns \\
\hline Gender $\rightarrow$ PersGr9 & .14 & .06 & .14 & .14 \\
\hline Gender $\rightarrow$ Grade Swedish & .24 & .23 & .23 & .24 \\
\hline Gender $\rightarrow$ InterSweGr6 & .16 & .10 & .20 & .18 \\
\hline Gender $\rightarrow$ InterSweGr9 & .12 & .21 & .24 & .23 \\
\hline
\end{tabular}




\begin{tabular}{|c|c|c|c|c|}
\hline & \multicolumn{4}{|c|}{ Model D3 Longitudinal Model - Mathematics } \\
\hline PersGr6 $\rightarrow$ PersGr9 & .34 & .30 & .35 & .29 \\
\hline PersGr6 $\rightarrow$ Grade Mathematics & ns & ns & ns & ns \\
\hline PersGr6 $\rightarrow$ InterMatGr9 & ns & .10 & .08 & .07 \\
\hline PersGr9 $\rightarrow$ Grade Mathematics & .16 & .10 & .08 & .09 \\
\hline InterMatGr6 $\rightarrow$ InterGr9 & .32 & .27 & .23 & .26 \\
\hline InterMatGr6 $\rightarrow$ Grade Mathematics & ns & ns & .08 & .05 \\
\hline InterMatGr6 $\rightarrow$ PersGr9 & ns & .10 & .08 & .10 \\
\hline InterMatGr9 $\rightarrow$ Grade Mathematics & .37 & .11 & .18 & .40 \\
\hline PersGr6 with InterMatGr6 & .46 & .36 & .37 & .38 \\
\hline PersGr9 with InterMatGr9 & .31 & .34 & .28 & .33 \\
\hline Gender $\rightarrow$ PersGr6 & ns & ns & ns & ns \\
\hline Gender $\rightarrow$ PersGr9 & .15 & .07 & .17 & .15 \\
\hline Gender $\rightarrow$ Grade Mathematics & ns & ns & -.06 & ns \\
\hline Gender $\rightarrow$ InterMatGr6 & ns & ns & ns & ns \\
\hline Gender $\rightarrow$ InterMatGr9 & ns & .06 & ns & ns \\
\hline
\end{tabular}

Note. PersGr6 - Perseverance grade 6, PersGr9 - Perseverance grade 9, InterEngGr6 - Interest in English grade 6, InterEngGr9 - Interest in English grade9, InterSweGr6 - Interest in Swedish grade 6, InterSweGr9 - Interest in Swedish grade 9, InterMatGr6 - Interest in Mathematics grade 6, InterMatGr9 - Interest in Mathematics grade 9, ns - non-significant estimate. ${ }^{1}$ Low SES - high achievement group. ${ }^{2}$ Low SES - low achievement group. ${ }^{3}$ High SES - low achievement group. ${ }^{4}$ High SES - high achievement group.

Table 4. Indirect Effects of Gender, Migration, Interest, and Perseverance in Grade 6 on the Subject Grades in English, Swedish and Mathematics

\begin{tabular}{|c|c|c|c|c|c|c|c|c|}
\hline & Total & $\begin{array}{c}\text { Total } \\
\text { Indirect }\end{array}$ & Total & $\begin{array}{c}\text { Total } \\
\text { Indirect }\end{array}$ & Total & $\begin{array}{c}\text { Total } \\
\text { Indirect }\end{array}$ & Total & $\begin{array}{c}\text { Total } \\
\text { Indirect }\end{array}$ \\
\hline & \multicolumn{2}{|c|}{ LSHA $^{1}$} & \multicolumn{2}{|c|}{ LSLA $^{2}$} & \multicolumn{2}{|c|}{ HSLA $^{3}$} & \multicolumn{2}{|c|}{$\mathrm{HSHA}^{4}$} \\
\hline & \multicolumn{8}{|c|}{ Model D1 Longitudinal Model English } \\
\hline Gender & ns & .06 & ns & .02 & ns & .03 & ns & .04 \\
\hline InterEngGr6 & .17 & .03 & .09 & .04 & .10 & .04 & .09 & .04 \\
\hline \multirow[t]{2}{*}{ PersGr6 } & ns & ns & .08 & .03 & .07 & .03 & ns & ns \\
\hline & \multicolumn{8}{|c|}{ Model D2 Longitudinal Model Swedish } \\
\hline Gender & .32 & .07 & .26 & .03 & .30 & .07 & .32 & .08 \\
\hline InterSweGr6 & .13 & .04 & ns & .04 & ns & .06 & .06 & .06 \\
\hline \multirow[t]{2}{*}{ PersGr6 } & ns & .09 & .12 & .06 & .09 & .07 & ns & .05 \\
\hline & \multicolumn{8}{|c|}{ Model D3 Longitudinal Model Mathematics } \\
\hline Gender & ns & ns & ns & ns & ns & .02 & ns & ns \\
\hline InterMatGr6 & .18 & .13 & ns & .04 & .13 & .05 & .16 & .12 \\
\hline PersGr6 & ns & .06 & .08 & .04 & ns & .04 & .07 & .06 \\
\hline
\end{tabular}

Note. PersGr6 - Perseverance grade 6, InterEngGr6 - Interest in English grade 6, InterSweGr6 - Interest in Swedish grade 6, InterMatGr6 - Interest in Mathematics grade 6, ns - non-significant estimate. ${ }^{1}$ Low SES - high achievement. ${ }^{2}$ Low SES - low achievement group. ${ }^{3}$ High SES - low achievement group. ${ }^{4}$ High SES - high achievement group.

It is evident that, both directly and indirectly, perseverance predicted subject grades in Swedish and Mathematics, but not English. For English, only interest in learning English was found to predict the subject grade. The lack of cross-lagged effects of grade 6 interest and perseverance seem to explain the relative success of the
LSHA group in Swedish and Mathematics. This implies that previous interest levels do not determine later perseverance levels and vice versa. However, for the LSHA group, the impact of being perseverant at grade 6 on later interest in English is noted. While only minor or no direct effects of gender could be found for English and Mathematics, the 
substantial direct effects of gender for Swedish indicate girls having higher grades. There were indirect effects of gender on the subject grades for both English and Swedish. However, this effect was only mediated through the interest dimension for English.

\section{DISCUSSION}

The present study investigated the association between grit facets, and the achievement of Swedish compulsory school students in three key school subjects: Swedish, English and Mathematics. The differentiated mechanisms of perseverance and interest in students' second language learning (i.e., English) can thus be highlighted and compared to those in Mathematics and Swedish both in diverse subgroups and in relation to gender.

For English language learning, perseverance does not provide any predictive power in relation to the subject grade in school grade 9. However, having consistency of interest is associated with English achievement. For Swedish and Mathematics, both perseverance of effort and interest in the subject are associated with achievement. Early grade perseverance has little or no direct importance for later performance in either Swedish or Mathematics. It is only the effects of early grade perseverance, mediated through later grade perseverance, that are important for these subjects. Thus, for Swedish and Mathematics, the results provide some support for the claims made by Duckworth et al. (2007). However, no support for these claims could be found in relation to L2 English.

The interest domain of grit was also an important predictor in all subjects. In previous studies, consistency of interest has provided little or no predictive power for achievement (i.e., Credé et al., 2017; Morell et al., 2020). In the present study, however, interest is defined as a schooland subject-specific construct, and it was measured over time. The longitudinal design also makes it possible to address the previous criticism of the grit scale as not reflecting the longevity aspect built into the concept (e.g., Dörnyei, 2020). This could also explain the difference in results compared to previous studies. Studies on L2 grit have also revealed that language-specific consistency of interest is predictive for achievement (e.g., Sudina et al., 2020; Teimouri et al., 2020). However, the pattern for interest differs somewhat between performance domains.
While having consistency in interest is favorable for all groups, and in all performance domains, early grade interest can also explain the results of the low-SES high-achieving students in the English performance domain. The same is true for the high-SES low-achieving, and the high-SES high-achieving groups in Mathematics. This implies that, while not being consistent in their interest, the early investment of interest pays off later for these students.

The nature of the performance domain could explain why perseverance of effort did not predict final grades in English. As Credé et al. (2017) have argued "grit may be an excellent predictor of an individual's ability to complete military basic training or succeed in well-defined academic tasks, but be less well related to performance on tasks that are very easy (thus not requiring grit)" (p. 7). Previous studies on English language learning indicate that in contexts where English is omnipresent in society-for example Sweden-students can experience proficiency in English classes as comfortably attainable (e.g., Henry \& Cliffordson, 2017). Consequently, students who do not experience a sense of challenge can view the classroom as "a welcome opportunity for rest and relaxation" (Henry, 2014, p. 111). In such circumstances, students are unlikely to be persistent and make investments of effort (Philip \& Duchesne, 2016). Thus it might be the case that in a context such as Sweden, English is a subject in school that does not require grit, at least not for the high achieving students.

Being high on grit leads individuals to engage in more practice and be less likely to be distracted in their studies (Duckworth \& Quinn, 2009; Duckworth et al., 2011). In this regard, Macnamara et al. (2014) found that the strength between deliberate practice and performance was much smaller in education than, for example, within music or when playing games. The results were interpreted to suggest that deliberate practice is less well defined within educational contexts. However, in the present study, the results suggest that different school subjects might also differ in relation to deliberate practice. While Mathematics and Swedish seem to require that students are perseverant and invest interest - i.e., needing to be gritty - it might also imply that, unlike English, these subjects can require more deliberate practice within the classroom in order to be successful.

Another possible explanation for the lack of grit in English might be found in the belief that languages are best 
learnt in natural settings, and that such a belief affects how students behave in formalized learning (Mercer \& Ryan, 2011). In contexts where English is ever-present - either in digital spaces or society at large - there is a risk that students fail to benefit from teaching due to the belief that English is best learned outside school (Henry \& Cliffordson, 2017). Research on the association between the amount of time invested in extramural English activities and achievement in school also offers support for such a belief (e.g., Sundqvist, 2009; Sundqvist \& Wikström, 2015) in that time spent engaging with English outside school pays off in terms of higher grades, hence, the investment takes place outside the classroom. Findings from the study by Sudina et al., (2020) also indicate that context affects students' inclinations to be gritty. While perseverance predicted selfperceived proficiency for EFL students, it did not contribute to predicting self-perceived proficiency for the ESL sample. Thus, the EFL learners in Japan and Korea in the study by Sudina and colleagues (2019) might not have the same opportunity to learn English in naturalistic settings such as those in the U.S. and Canada. However, even though perseverance of effort is not associated with English, having consistency of interests is. Busse (2017) identified similar results among Dutch students who experienced being both interested and engaged with English regardless of their enjoyment of learning the subject in the classroom, this being attributable to the importance of English in society. On the other hand, Feng and Papi (2020) found that valuing the language mediated the relation between perseverance and L2 persistence in the classroom. However, their study concerned learning Chinese in the U. S., an endeavor which might require more deliberate practice in the classroom due to the scarcer opportunities for spending time engaged with the language beyond the classroom.

Concerning the question as to possible differential effects of grit between different subgroups of students, the lack of cross-lagged effects of perseverance and interest for the high achieving low SES group in Swedish and Mathematics indicates that later perseverance (in grade 9) is not dependent on early interest (in grade 6) and vice versa. At the same time, perseverance in grade 9 is conditioned by grade 6 interest in the other groups. For the high achieving low SES group, a consistency of interest and perseverance over time are beneficial. Thus, the results indicate that grit is of particular importance when facing adversities, providing support for the claims made by Duckworth et al.
(2007). Specifically, the capacity for perseverance of effort and a consistency of interest seem to be of importance in explaining the relative success in school outcomes of the low SES students, at least in Swedish and Mathematics, a result similarly found by Thorsen et al. (2021).

There were also differences in the pattern of interest and perseverance due to gender. Previous studies have shown some gender differences in relation to grit, implying that girls are higher in grit than boys (e.g., Usher et al., 2019). The results in the present study are partially in line with these results. Girls rate themselves as higher in both perseverance and interest in both English and Swedish. However, for English, there were no direct effects of gender on the subject grade. Also, no gender differences were found for interest in Mathematics. While in our results, gender does not directly affect the subject grade in English, substantial gender differences were found for the subject grade in Swedish. Girls also see themselves higher in both perseverance and interest in Swedish. Therefore, the inconsistent results of the gender effects found in previous research might be due to the performance domain.

\section{Limitations}

One possible limitation in the present study could be found in the operationalization of interest and perseverance. The measurement of interest is narrower than initially defined by Duckworth et al., (2007). However, even though we only used one indicator, the longitudinal data allows for investigating the consistency of interest over time (as opposed to measuring it at a single time-point which is commonplace). The measurement of perseverance used in the present study does not entirely overlap with Duckworth's et al., (2007) original operationalization. However, it is well-aligned with the scales adopted for children used by Clark \& Malecki (2019). Even though the operationalization differs, we tested the model using the single items of perseverance, and the results largely agreed with those found with the factor score.

Additionally, the cutoff values of the SES-achievement groups gives room for arbitrary interpretations of group belongingness for individuals close to the cutoff region. However, measures were taken to justify the categorization (Thorsen et al., 2021). By regressing the GPA on measures of parents' highest education, it was found that the LSHA 
group scored 2.99 points higher than their predicted GPA, achieving on average a level of "pass with distinction" (thus indicating that this group is achieving higher than expected).

\section{CONCLUSION}

The results reveal that the value of grit in predicting achievement differs between different SES-achievement subgroups, and between different school subject domains. Being gritty is essential for achievement in Swedish and Mathematics in all subgroups. However, for L2 English learning, having a consistency of interest seems to be the only facet of the grit construct that influences students' achievement. Given that perseverance of effort significantly affected students' English learning outcomes in the total population (see results in Appendix), it might be reasonable to postulate that creating subgroups attenuates the relationship since the variance is reduced in the subgroups. However, the advantage of focusing on the subgroups is the ability to uncover possibly distinctive effect patterns of the grit facets of interest and perseverance within the more homogenous subpopulations (as such differential mechanisms cannot be detected with the full sample) (see results in Appendix). The estimates of effects are often concealed or inflated in the total population since the estimates of these associations in the entire sample were an average of the subgroup estimations and may point in different directions or vary largely in size.

Additionally, the results in the present study might be considered contradictory to recent arguments by Al-Hoorie and Hiver (2021), who have suggested that learning a language is, at the motivational level, not different from learning any other school subject. While the results of the current study do not suggest that the learning experience or the motivational aspects involved in learning differ per se, the social status of the L2 can mean that students are not required to be particularly gritty. Rather, it seems that the perseverance of effort may be invested beyond the classroom. As Dörnyei (2020) has suggested, "traits are not consistent across all situations and conditions" (p. 157). Consequently, grit might be more valuable in situations that are characterized by adversities and challenge which, in our results, is reflected in the relatively higher value of grit for the low SES high achievement group.

\section{Authors' contributions}

C.T. was involved in the design of the study, data preparation, data analysis, as well as the interpretation of the results. C.T. also drafted the article and was involved in the revision. S.J. was involved in the design of the study, the interpretation of results, as well as in the revision of the draft. $\mathrm{KYH}$ was involved in the design of the study, the interpretation of results, and the revision of the draft. C.T., S.J. and $\mathrm{KYH}$ were all involved in preparing the final version of the article.

\section{Ethics Approval \& Consent to Participate}

The data that support the findings of this study are available from University of Gothenburg. Restrictions apply to the availability of these data, which were used under license for this study. Data are available at https://ips.gu.se/english/research/research projects/ETF/access/?languageld=100001\&disableRedirect=true\&returnUrl=http\%3A\%2F\% 2Fips.gu.se $\% 2$ Fforskning\%2Fforskningsprojekt $\% 2 F u g u \% 2 F a c c e s s \% 2 F$ with the permission of University of Gothenburg.

\section{Funding}

The work is a part of the COMPASS project (Changes in the Compensatory Abilities in Supporting Academic Resilience in Swedish Schools over Time), which was supported financially by the Swedish Research Council. Grant number: 2018-05041.

\section{REFERENCES}

Al-Hoorie, A., \& Hiver, P. (2021). The fundamental difference hypothesis: Expanding the conversation in language learning motivation. SAGE Open. https://doi.org/10.1177\%2F2158244020945702
Bazelais, P., Lemey, D. J., \& Doleck, T. (2016). How does grit impact college students' academic achievement in science? European Journal of Science and Mathematics Education, 4(1), 33-43. https://eric.ed.gov/?id=EJ1107756 
Bowman, N. A., Hill, P. L., Denson, N., \& Bronkema, R. (2015). Keep on truckin' or stay the course? Exploring grit dimensions as differential predictors of educational achievement, satisfaction, and intentions. Social Psychological and Personality Science, 6(6) 639-645. https://doi.org/10.1177\%2F1948550615574300

Busse, V. (2017). Plurilingualism in Europe: Exploring attitudes toward English and other European languages among adolescents in Bulgaria, Germany, the Netherlands, and Spain. The Modern Language Journal, 101(3), 566-582. https://doi.org/10.1111/modl.12415

Chang, W. (2014). Grit and academic performance: Is being grittier better? [unpublished doctoral dissertation].

http://scholarlyrepository.miami.edu/cgi/viewcont ent.cgi?article2319\&contextoa dissertations

Changlek, A., \& Palanukulwong, T. (2015). Motivation and grit: Predictors of language learning achievement. Veridian E-Journal, 8(4), 23-36. https://he02.tci-thaijo.org/index.php/Veridian-EJournal/article/view/40089

Christensen, R., \& Knezek, G. (2014). Comparative measures of grit, tenacity and perseverance. International Journal of Learning, Teaching and Educational Research, 8(1), 16-30. http://ijlter.org/index.php/ijlter/article/view/151/61

Clark, K. N., \& Malecki, C. K. (2019). Academic grit scale: Psychometric properties and associations with achievement and life satisfaction. Journal of School Psychology, 72, 49-66. https://doi.org/10.1016/j.jsp.2018.12.001

Cormier, D. L., Dunn, J. G. H., \& Causgrove Dunn, J. (2019). Examining the domain specificity of grit. Personality and Individual Differences, 139(1), 349-354. https://doi.org/10.1016/j.paid.2018.11.026

Credé, M. (2018). What shall we do about grit? A critical review of what we know and what we don't know. Educational Researcher, 47(9), 606-611. https://doi.org/10.3102/0013189X18801322
Credé, M., Tynan, M., \& Harms, P. D. (2017). Much ado about grit: A meta-analytic synthesis of the grit literature. Journal of Personality and Social Psychology, 113(3), 492-511. https://doi.org/10.1037/pspp0000102

Datu, J. A. D., Valdez, J. P. M., \& King, R. B. (2016). Perseverance counts but consistency does not! Validating the short grit scale in a collectivist setting. Current Psychology: A Journal for Diverse Perspectives on Diverse Psychological Issues, 35(1), 121-130. https://doi.org/10.1007/s12144-015-9374-2

Disabato, D. J., Goodman, F. R., \& Kashdan, T. B. (2019). Is grit relevant to well-being and strengths? Evidence across the globe for separating perseverance of effort and consistency of interests. Journal of Personality, 87, 194-211. https://doi.org/10.1111/jopy.12382

Dörnyei, Z. (2020). Innovation and challenges in language learning motivation. Routledge.

Duckworth, A. L., \& Gross, J. J. (2014). Self-control and grit: Related but separable determinants of success. Current Directions in Psychological Science, 23(5), 319-325. https://doi.org/10.1177\%2F0963721414541462

Duckworth A. L., Kirby T. A., Tsukayama E., Berstein H., \& Ericsson K. A. (2011). Deliberate practice spells success: Why grittier competitors triumph at the National Spelling Bee. Social Psychological and Personality Science, 2(2), 174-181. https://doi.org/10.1177\%2F1948550610385872

Duckworth, A. L., Peterson, C., Matthews, M. D., \& Kelly, D. R. (2007). Grit: Perseverance and passion for long-term goals. Journal of Personality and Social Psychology, 92(6), 10871101. https://doi.org/10.1037/0022$\underline{3514.92 .6 .1087}$

Duckworth, A. L., \& Quinn, P. D. (2009). Development and validation of the short grit scale (Grit-S). Journal of Personality Assessment, 91(2), 166174. https://doi.org/10.1080/00223890802634290

Eskreis-Winkler, L., Shulman, E., Beal, S. A., \& Duckworth, A. (2014). The grit effect: predicting 
retention in the military, the work place, school and marriage. Frontiers in Psychology. https://doi.org/10.3389/fpsyg.2014.00036

Feng, L., \& Papi, M. (2020). Persistence in language learning: The role of grit and future self-guides. Learning and Individual Differences, 81. https://doi.org/10.1016/j.lindif.2020.101904

Henry, A. (2014). Swedish students' beliefs about learning English in and outside of school. In D.

Lasagabaster, A. Doiz, \& J.-M. Sierra (Eds). Motivation and foreign language learning: From theory to practice (pp. 93-116). John Benjamins.

Henry, A., \& Cliffordson, C. (2017). The impact of out-ofschool factors on motivation to learn English: Self-discrepancies, beliefs, and experiences of self-authenticity. Applied Linguistics, 38(5), 713736. https://doi.org/10.1093/applin/amv060

Hidi, S., \& Renninger, K. A. (2006). The four-phase model of interest development. Educational Psychologist, 41(2), 111-127.

https://doi.org/10.1207/s15326985ep4102_4

Hodge, B., Wright, B., \& Bennett, P. (2018). The role of grit in determining engagement and academic outcomes for university students. Research in Higher Education, 59, 448-460. https://doi.org/10.1007/s11162-017-9474-y

Huang, H., \& Zhu, H. (2017). High achievers from low socioeconomic backgrounds: The critical role of disciplinary climate and grit. Mid-Western Educational Researcher, 29(2), 93-116. https://www.mwera.org/MWER/volumes/v29/issu e2/V29n2-Huang-FEATURE-ARTICLE.pdf

Härnqvist, K. (2000). Evaluation through follow-up. A longitudinal program for studying education and career development. In C.-G. Janson (Ed.), Seven Swedish longitudinal studies in behavioral science (pp. 76-114). Forskningsrådsnämnden.

Jiang, W., Xiao, Z., Liu, Y., Guo, K., Jiang, J., \& Du, X. (2019). Reciprocal relations between grit and academic achievement: A longitudinal study. Learning and Individual Differences, 71, 13-22. https://doi.org/10.1016/j.lindif.2019.02.004
Khajavy, G., MacIntyre, P., \& Hariri, J. (2021). A closer look at grit and language mindsets as predictors of foreign language achievement. Studies in Second Language Acquisition, 43(2), 379-402. https://doi.org/10.1017/S0272263120000480

Kline, R. B. (2015). Principles and practice of structural equation modeling (4th ed). Guilford Press.

Li, J., Zhao, Y., Kong, F., Du, S., Yang, S., \& Wang, S. (2018). Psychometric assessment of the short grit scale among Chinese adolescents. Journal of Psychoeducational Assessment, 36(3), 291-296. https://doi.org/10.1177/0734282916674858

Light, A., \& Nencka, P. (2019). Predicting educational attainment: Does grit compensate for low levels of cognitive ability? Learning and Individual Differences, 70, 142-154. https://doi.org/10.1016/j.lindif.2019.02.002

Macnamara, B. N., Hambrick, D. Z., \& Oswald, F. L. (2014). Deliberate practice and performance in music, games, sports, education, and professions: A meta-analysis. Psychological Science, 25(8), 13. https://doi.org/10.1177\%2F0956797614535810

Mercer, S., \& Ryan, S. (2010). A mindset for EFL: Learners' beliefs about the role of natural talent. ELT Journal, 64, 436-444. https://doi.org/10.1093/elt/ccp083

Morell, M., Yang, J. S., Gladstone, J. R., Turci Faust, L., Ponnock, A. R., Lim, H. J., \& Wigfield, A. (2021). Grit: The long and short of it. Journal of Educational Psychology, 113(5), 1038-1058. https://doi.org/10.1037/edu0000594

Muenks, K., Wigfield, A., Yang, J. S., \& O’Neal, C. R. (2017). How true is grit? Assessing its relations to high school and college students' personality characteristics, self-regulation, engagement, and achievement. Journal of Educational Psychology, 109(5), 599-620. https://doi.org/10.1037/edu0000153

Muthén, L., \& Muthén, B. (1998-2018). Mplus user's guide (8th ed.). Muthén \& Muthén. https://www.statmodel.com/download/usersguide/ MplusUserGuideVer_8.pdf 
Philip, J., \& Duchesne, S. (2016). Exploring engagement in tasks in the language classroom. Annual Review of Applied Linguistics, 36, 50-72. https://doi.org/10.1017/S0267190515000094

Rimfeld, K., Kovas, Y., Dale, P. S., \& Plomin, R. (2016). True grit and genetics: Predicting academic achievement from personality. Journal of Personality and Social Psychology, 111(5), 780 789. http://doi.org/10.1037/pspp0000089

Schmidt, F. T. C., Fleckenstein, J., Retelsdorf, J., EskreisWinkler, L., \& Möller, J. (2017). Measuring grit: A German validation and a domain-specific approach to grit. European Journal of Psychological Assessment, 35(3), 436-447. https://doi.org/10.1027/1015-5759/a000407

Sudina, E., Brown, J., Datzman, B , Oki, Y., Song, K., Cavanaugh, R., Thiruchelvam, B., \& Plonsky, L. (2021). Language-specific grit: Exploring psychometric properties, predictive validity, and differences across contexts. Innovation in Language Learning and Teaching, 15(4), 334351.

https://doi.org/10.1080/17501229.2020.1802468

Sundqvist, P. (2009). Extramural English matters: Out-ofschool English and its impact on Swedish ninth graders' oral proficiency and vocabulary. [unpublished doctoral dissertation] Karlstad University Studies. https://www.divaportal.org/smash/get/diva2:275141/FULLTEXT03

Sundqvist, P., \& Sylvén, L. K. (2012). World of VocCraft: Computer games and Swedish learners' L2 English vocabulary. In H. Reinders (Ed.), Digital games in language learning and teaching (pp. 189-208). Palgrave Macmillan.

Sundqvist, P., \& Sylvén, L. K. (2014). Language-related computer use: Focus on young L2 English learners in Sweden. ReCALL, 26(1), 3-20. https://doi.org/10.1017/S0958344013000232

Sundqvist, P., \& Wikström, P. (2015). Out-of-school digital gameplay and in-school L2 English vocabulary outcomes. System, 51, 65-71. https://doi.org/10.1016/j.system.2015.04.001
Svensson, A., Nielsen, B., \& Berndtsson, Å. (2007). Kodning av föräldrars utbildning baserad på SUN 2000 (Vol. 1). Teknisk rapport 2007:1. Göteborgs Universitet. Institutionen för pedagogik och didaktik. [Coding of parents' education based on SUN2000 (Vol 1). Technical report 2007:1]. University of Gothenburg. The institution for education and didactics.

https://www4.gu.se/compeat/FUR/GOLD/TR/TR2 $\underline{007 \text { 1.pdf }}$

Swedish Schools Inspectorate (2011).

Kvalitetsgranskning: Engelska i grundskolans årskurser 6-9. [Quality evaluation: English in secondary school grades 6-9]. Stockholm: Swedish Government.

https://www.skolinspektionen.se/beslut-rapporterstatistik/publikationer/kvalitetsgranskning/2011/en gelska-i-grundskolans-arskurser-69/

Thorsen, C., Yang Hansen, K., \& Johansson, S. (2021). The mechanisms of interest and perseverance in predicting achievement among academically resilient and non-resilient students: Evidence from Swedish longitudinal data. British Journal of Educational Psychology. Advance online publication. https://doi.org/10.1111/bjep.12431

Teimouri, Y., Plonsky, L., \& Tabandeh, F. (2020). L2 Grit: Passion and perseverance for second-language learning. Language Teaching Research. Advance online publication. https://doi.org/10.1177\%2F1362168820921895

Usher, E. L., Li, C. R., Butz, A. R., \& Rojas, J. P. (2019). Perseverant grit and self-efficacy: Are both essential for children's academic success? Journal of Educational Psychology, 111(5), 877-902. https://doi.org/10.1037/edu0000324

Ushioda, E. (2013). Motivation and ELT: Global issues and local concerns. In E, Ushioda. (Ed.), International perspectives on motivation: Language learning and professional challenges (pp. 1-17). Palgrave Macmillan.

Vaino, M. M., \& Daukantaitè, D. (2016). Grit and different aspects of well-Being: Direct and indirect relationships via sense of coherence and authenticity. Journal of Happiness Studies, 17(5), 
2119-2147. https://doi.org/10.1007/s10902-0159688-7.

Wei, H., Gao, K., \& Wang, W. (2019). Understanding the relationship between grit and foreign language performance among middle school students: The roles of foreign language enjoyment and classroom environment. Frontiers in Psychology, 10,1-8. https://doi.org/10.3389/fpsyg.2019.01508
Wei, R., Liu, H., \& Wang, S. (2020). Exploring L2 grit in the Chinese EFL context, System, 93, 1-9. https://doi.org/10.1016/j.system.2020.102295

Wolters, C. A., \& Hussain, M. (2015). Investigating grit and its relations with college students' selfregulated learning and academic achievement. Metacognition and Learning, 10(3), 293-311. https://doi.org/10.1007/s11409-014-9128-9 


\section{APPENDIX}

This appendix contains information on the principal component analysis conducted to create a continuous perseverance variable. This appendix also contains the results from modeling of the full sample.

Principal component analysis was conducted to create a continuous Perseverance variable using the regression method and values excluded listwise. Only one factor was extracted for each grade. All factor loadings were substantial (Table A1).

Table A1. Factor loadings from principal component analysis of perseverance in grade 6 and 9

\begin{tabular}{lcc}
\hline & Grade 6 & Grade 9 \\
\hline Get things done in time & .70 & .74 \\
Work hard even when difficult & .78 & .85 \\
Always do my best & .74 & .80 \\
Easily give up & .58 & .63 \\
\hline Percentage of variance & 49.69 & 57.58 \\
Eigenvalue & 1.99 & 2.30 \\
coefficient alpha & .68 & .75 \\
\hline
\end{tabular}

Note. Principal component analysis, unrotated solution. Only one factor was extracted for each grade with eigenvalue $>1$.

The descriptive statistics for all variables can be found in Table A2. The missingness is generally small for all variables. The correlation between all variables can be found in Table A3. The correlations reveal that both interest and perseverance in grade 6 is moderately correlated with the different subject grades. The correlations between interest and perseverance in grade 9 are more substantially correlated.

Table A2. Descriptive Statistics for the entire sample, divided by Grade 6 and Grade 9

\begin{tabular}{lcccccc}
\hline \multirow{2}{*}{ Variables } & $N$ & $M$ & $S D$ & $N$ & $M$ & $S D$ \\
\cline { 2 - 7 } & \multicolumn{7}{c}{ Grade 6 } & \multicolumn{7}{c}{ Total group } \\
\cline { 2 - 6 } & \multicolumn{7}{c}{ Grade 9 } \\
\hline Grade English & & & 4941 & 14.33 & 4.30 \\
Grade Swedish & & & 4830 & 14.26 & 4.07 \\
Grade Mathematics & 4895 & 0.00 & 1.00 & 4941 & 13.01 & 4.56 \\
Perseverance total & 4976 & 0.00 & 1.00 & 4966 & 0.00 & 1.00 \\
Get things done in time & 4952 & 0.00 & 1.00 & 4964 & 0.00 & 1.00 \\
Work hard even when difficult & 4931 & 0.00 & 1.00 & 4963 & 0.00 & 1.00 \\
Always do my best & 4987 & 0.00 & 1.00 & 4985 & 0.00 & 1.00 \\
Easily give up & 4988 & 0.00 & 1.00 & 4967 & 0.00 & 1.00 \\
Interest in English & 4992 & 0.00 & 1.00 & 4979 & 0.00 & 1.00 \\
Interest in Swedish & 4979 & 0.00 & 1.00 & 4958 & 0.00 & 1.00 \\
Interest in Mathematics & & & & & & \\
\hline
\end{tabular}


Table A3. Correlation matrix for variables included in the study

\begin{tabular}{|c|c|c|c|c|c|c|c|c|c|c|c|}
\hline & GREN & GRSV & GRMA & PersGr6 & PersGr9 & InterEnGr6 & InterSwGr6 & InterMaGr6 & InterEnGr9 & InterSwGr9 & InterMaGr9 \\
\hline GREN & 1 & & & & & & & & & & \\
\hline GRSV & $.66^{* *}$ & 1 & & & & & & & & & \\
\hline GRMA & $.56^{\star *}$ & $.61^{* *}$ & 1 & & & & & & & & \\
\hline PersGr6 & $.16^{* *}$ & $.16^{* *}$ & $.19^{* *}$ & 1 & & & & & & & \\
\hline PersGr9 & $.23^{\star *}$ & $.33^{* *}$ & $.29^{* *}$ & $.37^{* *}$ & 1 & & & & & & \\
\hline InterEnGr6 & $.14^{* *}$ & $.09^{* *}$ & $.05^{* *}$ & $.29^{* *}$ & $.17^{* *}$ & 1 & & & & & \\
\hline InterSwGr6 & -.01 & $.07^{* *}$ & .00 & $.31^{* *}$ & $.20^{* *}$ & $.43^{* *}$ & 1 & & & & \\
\hline InterMaGr6 & -.01 & $.04^{* *}$ & $.13^{* *}$ & $.38^{* *}$ & $.21^{* *}$ & $.37^{* *}$ & $.43^{* *}$ & 1 & & & \\
\hline InterEnGr9 & $.31^{* *}$ & $.29^{* *}$ & $.18^{* *}$ & $.16^{* *}$ & $.35^{\star *}$ & $.24^{* *}$ & $.15^{\star *}$ & $.09^{* *}$ & 1 & & \\
\hline InterSwGr9 & $.16^{\star *}$ & $.33^{* *}$ & $.11^{* *}$ & $.17^{* *}$ & $.37^{* *}$ & $.18^{* *}$ & $.26^{* *}$ & $.13^{* *}$ & $.54^{* *}$ & 1 & \\
\hline InterMaGr9 & $.13^{* *}$ & $.19^{* *}$ & $.35^{\star *}$ & $.20^{* *}$ & $.40^{* *}$ & $.13^{* *}$ & $.15^{* *}$ & $.29^{* *}$ & $.38^{* *}$ & $.41^{* *}$ & 1 \\
\hline
\end{tabular}

Note. GREN - subject grade English, GRSV - subject grade Swedish, GRMA - subject grade Mathematics, PersGr6 - perseverance grade 6, PersGr9 perseverance grade 9, InterEnGr6 - interest in English grade 6, InterSwGr6 - interest in Swedish grade 6, InterMaGr6 - interest in Mathematics grade 6, InterEnGr9 - interest in English grade 9, InterSwGr9 - interest in Swedish grade 6, InterMaGr9 - interest in Mathematics grade 9. 
Result from the one-time modeling of the full sample.

The result of the one-time modeling of the total sample revealed effects of both early grade perseverance (.11) and later grade perseverance (.12) on the subject grade in English. There also were substantial effects of later grade interest on the subject grade in English (.27). For Swedish there were effects of both early grade perseverance (.14) and later grade perseverance (.24). Early grade interest was only related (.02) to the subject grade while later grade interest was related (.25). For Mathematics there were effects of both early grade perseverance (.13) and later grade perseverance (.17). While early grade interest only was related to the subject grade in Mathematics (.07) later grade interest had a substantial effect (.29). The R2 was generally low for all models (Table A4).

Table A4. Standardized effects from the one-time path modeling with the subject grades of English, Swedish and Mathematics as outcomes

Standardized effect

PersGr6 $\rightarrow$ Grade English

English Grade 6

InterEngGr6 $\rightarrow$ Grade English

PersGr6 withInterEngGr6

$R 2$

English Grade 9

PersGr9 $\rightarrow$ Grade English

InterEngGr9 $\rightarrow$ Grade English

PersGr9 with InterEngGr9

R2

PersGr6 $\rightarrow$ Grade Swedish

Swedish Grade 6

InterSweGr6 $\rightarrow$ Grade Swedish

PersGr6 with InterSweGr6

R2

PersGr9 $\rightarrow$ Grade Swedish

Swedish Grade 9

InterSweGr9 $\rightarrow$ Grade Swedish

PersGr9 withlnterSweGr9

R2

PersGr6 $\rightarrow$ Grade Mathematics

Mathematics Grade 6

InterMatGr6 $\rightarrow$ Grade Mathematics

PersGr6 with InterMatGr6

$R 2$

PersGr9 $\rightarrow$ Grade Mathematics

Mathematics Grade 9

InterMatGr9 $\rightarrow$ Grade Mathematics

PersGr9 with InterMatGr9

$R 2$

Note. PersGr6 - Perseverance grade 6, PersGr9 - Perseverance grade 9, InterEngGr6 - Interest in English grade 6, InterEngGr9 - Interest in English grade9, InterSweGr6 - Interest in Swedish grade 6, InterSweGr9 - Interest in Swedish grade 9, InterMatGr6 - Interest in Mathematics grade 6, InterMatGr9 - Interest in Mathematics grade 9. 
Result from the longitudinal modeling of the full sample.

The longitudinal modeling revealed that there were direct effects of early grade perseverance $(.07)$ and later grade perseverance $(.10)$ on the English grade. There was also a direct effect of early grade interest (.04) and later grade interest (.26) on the subject grade in English. We found direct effects of early grade perseverance (.07) and later grade perseverance (.23) on the subject grade in Swedish. Interestingly, there was a negative effect of early grade interest (-.08) while there was a positive effect of later grade interest (.21) on the Swedish grade. We also identified a direct effect of early grade perseverance (.08) and later grade perseverance (.16) on the subject grade in Mathematics. Early grade interest did not directly predict the subject grade in Mathematics, although later grade interest did (.28). In all models there were cross-lagged effects implying that early grade interest affected later grade perseverance and vice versa (Table A5).

Table A5. Standardized effects of the longitudinal modeling with subject grades English, Swedish and Mathematics as distal outcomes

\section{Longitudinal Model English}

PersGr6 $\rightarrow$ PersGr9

Standardized effect

PersGr6 $\rightarrow$ Grade English

PersGr6 $\rightarrow$ InterEngGr9

PersGr9 $\rightarrow$ Grade English

InterEngGr6 $\rightarrow$ InterEngGr9

InterEngGr6 $\rightarrow$ Grade English

InterEngGr6 $\rightarrow$ PersGr9

InterEngGr9 $\rightarrow$ Grade English

PersGr6 with InterEngGr6

PersGr9 with InterEngGr9

Gender $\rightarrow$ PersGr6

Gender $\rightarrow$ PersGr9

Gender $\rightarrow$ Grade English

Gender $\rightarrow$ InterEngGr6

Gender $\rightarrow$ InterEngGr9

PersGr6 $\rightarrow$ PersGr9

PersGr6 $\rightarrow$ Grade Swedish

PersGr6 $\rightarrow$ InterSweGr9

PersGr9 $\rightarrow$ Grade Swedish

InterSweGr6 $\rightarrow$ InterSweGr9

InterSweGr6 $\rightarrow$ Grade Swedish

InterSweGr6 $\rightarrow$ PersGr9

InterSweGr9 $\rightarrow$ Grade Swedish

PersGr6 with InterSweGr6

PersGr9 with InterSweGr9

Gender $\rightarrow$ PersGr6

Gender $\rightarrow$ PersGr9

Gender $\rightarrow$ Grade Swedish

Gender $\rightarrow$ InterSweGr6

Gender $\rightarrow$ InterSweGr9

PersGr6 $\rightarrow$ PersGr9

PersGr6 $\rightarrow$ Grade Mathematics
Longitudinal Model Swedish

Longitudinal Model Mathematics 
\begin{tabular}{lr} 
PersGr6 $\rightarrow$ InterMatGr9 & .11 \\
PersGr9 $\rightarrow$ Grade Mathematics & .16 \\
InterMatGr6 $\rightarrow$ InterMatGr9 & .25 \\
InterMatGr6 $\rightarrow$ Grade Mathematics & $\mathrm{ns}$ \\
InterMatGr6 $\rightarrow$ PersGr9 & .08 \\
InterMatGr9 $\rightarrow$ Grade Mathematics & .28 \\
PersGr6 with InterMatGr6 & .38 \\
PersGr9 with InterMatGr9 & .34 \\
Gender $\rightarrow$ PersGr6 & .03 \\
Gender $\rightarrow$ PersGr9 & .15 \\
Gender $\rightarrow$ Grade Mathematics & $\mathrm{ns}$ \\
Gender $\rightarrow$ InterMatGr6 & $\mathrm{ns}$ \\
Gender $\rightarrow$ InterMatGr9 & .04 \\
\hline
\end{tabular}

Note. Abbreviations are: PersGr6 - Perseverance grade 6, PersGr9 - Perseverance grade 9, InterEngGr6 - Interest in English grade 6, InterEngGr9 - Interest in English grade9, InterSweGr6 - Interest in Swedish grade 6, InterSweGr9 Interest in Swedish grade 9, InterMatGr6 - Interest in Mathematics grade 6, InterMatGr9 - Interest in Mathematics grade 9. 